\title{
60S Acidic Ribosomal Protein P0
}

National Cancer Institute

\section{Source}

National Cancer Institute. 60S Acidic Ribosomal Protein P0. NCI Thesaurus. Code C148009.

605 acidic ribosomal protein P0 (317 aa, $\sim 34 \mathrm{kDa}$ ) is encoded by the human RPLP0 gene. This protein plays a role in ribosome structure. 